\title{
Conservação de mangabas submetidas à aplicação de quitosana
}

\section{Mangaba fruits conservation with chitosan application}

\section{Flávia Aparecida de Carvalho MARIANO-NASSER ${ }^{1,2}$; Aparecida Conceição BOLIANI ${ }^{3}$; Mauricio Dominguez NASSER ${ }^{4}$; Maximiliano Kawahata PAGLIARINI ${ }^{5}$; Veridiana Zocoler MENDONÇA ${ }^{6}$}

\begin{abstract}
${ }^{1}$ Este trabalho é parte da tese de doutorado da primeira autora e foi financiado pela Fundação de Amparo à Pesquisa do Estado de São Paulo.

${ }^{2}$ Autor para correspondência, Engenheira-Agrônoma, Pós-doutoranda. Departamento de Horticultura, Universidade Estadual Paulista, Campus Botucatu, Rua José Barbosa de Barros, 1780 - CEP 18610-307 Botucatu, São Paulo, Brasil. flaviamariano1@hotmail.com

${ }^{3}$ Engenheira-Agrônoma, Doutora. Docente do Departamento de Fitotecnia, Tecnologia de Alimentos e Sócio Economia, Universidade Estadual Paulista, Campus Ilha Solteira, Passeio Monção, 226, 15385-000, Ilha Solteira, São Paulo, Brasil.boliani@agr.feis.unesp.br

4 Engenheiro-Agrônomo, Doutorando. Pesquisador Cientifico da Agência Paulista de Tecnologia dos Agronegócios, Regional de Adamantina, Estrada 14 Km 6, Adamantina, São Paulo, Brasil.mdnasser@apta.gov.br

${ }^{5}$ Engenheiro-Agrônomo, Mestre. Departamento de Fitotecnia, Tecnologia de Alimentos e Sócio Economia, Universidade Estadual Paulista, Campus Ilha Solteira, Passeio Monção, 226, 15385-000, Ilha Solteira, São Paulo, Brasil

${ }^{6}$ Engenheira Agrônoma, Mestre. Energia na Agricultura, Universidade Estadual Paulista, Campus Botucatu, Rua José Barbosa de Barros, 1780 - CEP 18610-307Botucatu, São Paulo, Brasil
\end{abstract}

\section{Recebido em: 27-03-2015; Aceito em: 03-03-2016}

\section{Resumo}

Objetivou-se avaliar as aplicações de quitosana como película comestível na pós-colheita de mangabas. Foram utilizadas mangabas colhidas no estádio de vez. Após a lavagem, higienização e secagem ao ar, os frutos foram acondicionados em bandejas de poliestireno expandido com capacidade de $200 \mathrm{~g}$ e recobertos com filme PVC com $12 \mu \mathrm{m}$. Os frutos receberam os seguintes tratamentos: T1- sem quitosana (controle); T2- quitosana 0,25\%; T3- quitosana 0,5\%; T4- quitosana 1\% e T5- quitosana $2 \%$. As bandejas foram armazenadas em temperatura controlada durante 15 dias. A cada três dias, foram realizadas as avaliações de perda de massa, dos teores de ácido ascórbico, de sólidos solúveis, de acidez titulável e de açúcar redutor, além do $\mathrm{pH}$ e da aparência visual. $\mathrm{O}$ delineamento experimental utilizado foi o inteiramente casualizado, em esquema fatorial (concentração de quitosana $x$ tempo de armazenamento). Os resultados foram submetidos ao teste $F(p<0,05)$ e à regressão polinomial. Concentrações de $1 \%$ e $2 \%$ mostram-se efetivas na aparência visual das mangabas, permitindo armazená-las por 15 dias.

Palavras-chave adicionais: armazenamento; Hancornia speciosa Gomes; película comestível; pós-colheita.

\begin{abstract}
This study aimed to evaluate the chitosan application as comestible film in mangaba post-harvested fruits. Semi-mature stage fruits were harvested for the research. After washing, sanitizing and air drying, the fruits were packed in expanded polystyrene trays with $200 \mathrm{~g}$ capacity and covered with $12 \mu \mathrm{m}$ PVC film. The fruits received the following treatments: T1 - without chitosan (control); T2 - chitosan $0.25 \%$; T3 - chitosan $0.5 \%$; $\mathrm{T} 4$ - chitosan $1 \%$ and $\mathrm{T} 5$ - chitosan $2 \%$. The trays were stored at controlled temperature for 15 days. Every three days were evaluated loss of mass, ascorbic acid, soluble solids, titratable acidity, pH, reducing sugar and visual appearance. The experimental design was completely randomized in a factorial scheme (chitosan concentration $x$ storage time). The results were analysed by $F$ test $(p<0.05)$ and polynomial regression. Concentrations of $1 \%$ and $2 \%$ shown to be effective in Hancornia speciosa fruits visual appearance allowing store them for 15 days.
\end{abstract}

Additional keywords: edible film; Hancornia speciosa Gomes; post-harvest; storage.

\section{Introdução}

A mangabeira (Hancornia speciosa Gomes) é uma espécie tropical, originária do Brasil, e pode ser encontrada em diversas regiões do País. É uma das frutas mais ricas em ferro e boa fonte de ácido ascórbico (vitamina C) (Silva Júnior, 2004). A associação de ferro e ácido ascórbico é um atributo importante na composição da mangaba, uma vez que a vitamina $C$ aumenta a biodisponibilidade de ferro no organismo, além de ser um excelente oxidante (Embrapa, 2010, Carnelossi et al., 2009, Chitarra \& Chitarra, 2005).

Os frutos e a polpa da mangaba possuem boa aceitação de consumo em suas regiões de ocorrência, tanto o fruto in natura como os produtos elaborados (sorvetes, geleias, licores, sucos, iogurtes, entre outros) (Cardoso et al., 2014). No entanto, 
os frutos apresentam curta vida pós-colheita devido à alta perecibilidade, à maturação rápida com difícil ponto de determinação de colheita, casca frágil e aos danos e sujeira causados pela queda dos frutos no chão (Embrapa, 2010), limitando, assim, a exploração da cultura (Vieira et al., 2010).

Uma alternativa para reduzir as perdas póscolheita é a aplicação de tecnologia adequada para prevenir e/ou retardar a deterioração de frutas e hortaliças (Durigan, 2013). Estudos recentes relatam que a aplicação do revestimento de quitosana pode ser usada como um conservante eficaz para a manutenção da qualidade e do prolongamento da vida de prateleira de vários frutos e hortaliças altamente perecíveis (Hong et al., 2012), como a mangaba. A quitosana é um polímero biodegradável de elevado peso molecular, não tóxico e com potencial para conferir numerosas propriedades fisiológicas e biológicas com aplicação em uma ampla gama de indústrias, incluindo a de alimentos. Tornou-se um composto útil devido a seus efeitos fungicidas e à elicitação de mecanismos de defesa em tecidos vegetais (Bautista-Baños et al., 2006; Hong et al., 2012).

A quitosana forma uma película semipermeável que regula a troca de gases e reduz a taxa de respiração, consequentemente o processo de maturação do fruto é retardado, e a perda de água, diminuída (Bautista-Baños et al., 2006, Chitarra \& Chitarra, 2005), sem, no entanto, causar bloqueio das reações metabólicas (Cerqueira et al., 2011).

Nesse contexto, o objetivo deste trabalho foi avaliar o potencial de diferentes concentrações de quitosana na extensão do período de armazenamento de frutos de mangaba.

\section{Material e métodos}

O experimento foi desenvolvido em agosto/setembro de 2013, no Laboratório de Tecnologia de Alimentos, da Universidade Estadual Paulista "Júlio de Mesquita Filho" (UNESP), Câmpus de llha Solteira - SP, com frutos produzidos em uma propriedade rural no município de Caçu - GO.

Os frutos foram colhidos no estádio de maturação de vez, classificados subjetivamente pela cor da casca (amarelo-esverdeada) e firmeza dos frutos (levemente duros), com cerca de 100 dias após a floração. Os frutos foram acondicionados em caixas plásticas e levados ao laboratório onde foram selecionados, eliminando os que apresentavam danos físicos e biológicos. Posteriormente, foram lavados e higienizados com hipoclorito de sódio (100 $\mathrm{mg} \mathrm{L}^{-1}$ ) por 10 minutos e novamente lavados em água corrente para retirada de resíduos e excesso do cloro; posteriormente, os frutos foram secos ao ar (Pereira et al., 2010, Narain \& Ferreira, 2003).

A quitosana foi dissolvida nas concentrações: $0 \% ; 0,25 \% ; 0,5 \% ; 1 \%$ e $2 \%$ p/v (quitosana em água) utilizando $1 \%$ de ácido acético, resultando em cinco tratamentos, em que: T1- sem aplicação de quitosana; T2 - aplicação de quitosana 0,25\%; T3 - aplicação de quitosana 0,5\%; T4 - aplicação de quitosana $1 \%$ e T5 - aplicação de quitosana $2 \%$. Os biofilmes foram obtidos por meio de agitação magnética, até a dissolução completa da solução. As mangabas foram divididas em cinco grupos e foram acondicionadas em bandejas de poliestireno expandido $(18 \times 12,5 \times 4 \mathrm{~cm})$ com capacidade de $200 \mathrm{~g}$.

$O$ delineamento experimental utilizado foi 0 inteiramente casualizado, em esquema fatorial $(5 \mathrm{x}$ 6 ), sendo cinco concentrações de quitosana em seis períodos de avaliações (0;3; 6; 9; 12 e 15 dias), com duas repetições por tratamento, sendo cada repetição composta por seis frutos.

A aplicação das soluções foi realizada com esborrifador até que os frutos estivessem totalmente cobertos. Após receberem os tratamentos, as bandejas de poliestireno expandido foram revestidas com filme de Policloreto de Vinila (PVC) de $12 \mu \mathrm{m}$, sendo armazenadas em temperatura controlada a $3 \pm 1{ }^{\circ} \mathrm{C}$ e $80 \pm 1 \%$ de umidade em B. O. D., durante os 15 dias. Apesar de ser um fruto tropical, em teste preliminar, a temperatura de $3 \pm 1 \stackrel{\circ}{\circ}$ foi a que melhor promoveu a conservação em prateleira, não ocorrendo prejuízos à coloração e à qualidade dos frutos.

As características avaliadas foram: perda de massa (\%), teor de ácido ascórbico (mg de ácido ascórbico $100 \mathrm{~g}^{-1}$ de polpa), acidez titulável ( $\mathrm{g}$ de ácido cítrico $100 \mathrm{~g}^{-1}$ de polpa) (Instituto Adolfo Lutz, 1985), sólidos solúveis (ํㅏix), pH, açúcares redutores em porcentagem (método Lane-Eynon) e aparência visual, sendo utilizada uma escala de 1 a 5 (1 - Inaceitável; 2 - Ruim; 3 - Regular; 4 - Bom; 5 - Ótimo). A avaliação de aparência visual foi realizada pelos pesquisadores, para cada unidade experimental, determinando-se ao final 0 valor médio das notas dadas.

Os resultados foram submetidos à análise de variância pelo teste $\mathrm{F}$, ao nível de $5 \%$ de probabilidade. As interações significativas foram desdobradas via análise de regressão, e as análises foram feitas com auxílio do programa estatístico SISVAR (Ferreira, 2010).

\section{Resultados e discussão}

As concentrações de quitosana aplicadas nos frutos não influenciaram o teor de ácido ascórbico, sólidos solúveis, acidez titulável, pH e açúcar redutor (Tabela 1).

A perda de massa foi influenciada pelo tratamento e ao longo do armazenamento (Figura 1). Observa-se que os frutos de mangaba, em todos os tratamentos, apresentaram perda de massa com 0 período de armazenamento. Entretanto, os frutoscontrole apresentaram maior perda nos seis primeiros dias de prateleira $(1,79 \%)$, quando comparados com os frutos que receberam o filme de quitosana. Os filmes de quitosana, provavelmente, funcionaram como barreira contra perda de água e modificaram o 
ambiente ao redor dos frutos, dificultando a entrada do oxigênio do ambiente e a perda do $\mathrm{CO}_{2}$, reduzindo assim a respiração dos frutos climatéricos. Chitarra \& Chitarra (2005) citam que os filmes ou os revestimentos comestíveis não são substitutos da embalagem convencional, porém atuam como coadjuvante, formam fina camada ao redor dos produtos, regulando as trocas gasosas e as perdas de vapor d'água que contribuem para a redução da perda de massa e da perda de voláteis responsáveis pelo aroma e pelo sabor dos frutos.
Em pesquisa com goiaba cv. Pedro Sato (Soares et al., 2011), manga cv. Tommy Atkins (Souza et al., 2011), morango (Hernández-Muñoz et al., 2008) e pseudofruto do cajueiro (Ferreira et al., 2010) observaram-se menores perdas de massa fresca em frutos tratados com película de quitosana, quando comparados com os frutos-controle. Tezotto-Uliana et al. (2014) trabalharam com framboesas e apontaram doses de $1 \%$ e $2 \%$ de quitosana como eficazes na manutenção do peso dos frutos em pós-colheita.

Tabela 1 - Valores do quadrado médio e dos níveis de significância das características avaliadas dos frutos de mangabeira sob ação de concentrações de filmes de quitosana $(0,25 ; 0,5 ; 1$ e $2 \%)$, ao longo de 15 dias de armazenamento a $3 \pm 1^{\circ} \mathrm{C}$ e $80 \pm 1 \%$ de UR. Ilha Solteira, 2013. Square mean values and significance levels of mangaba assessed fruit traits in chitosan film concentration action (0.25, 0.5, 1 and 2\%) and control, for 15 days of storage at $3 \pm 1{ }^{\circ} \mathrm{C}$ and $80 \pm 1 \% R H$. Ilha Solteira, 2013.

\begin{tabular}{lcccccccc}
\hline Variação & $\mathrm{GL}$ & $\mathrm{PM}$ & $\mathrm{AA}$ & $\mathrm{SS}$ & $\mathrm{AT}$ & $\mathrm{pH}$ & $\mathrm{AR}$ & $\mathrm{AV}$ \\
\hline Doses & 4 & $0,283^{*}$ & $212,2^{*}$ & $1,441^{\text {ns }}$ & $0,001^{\text {ns }}$ & $0,005^{\text {ns }}$ & $0,091^{\text {ns }}$ & $2,183^{* *}$ \\
Tempo & 5 & $9,736^{*}$ & $12893,9^{\text {ns }}$ & $4,394^{\text {ns }}$ & $0,013^{*}$ & $0,072^{* *}$ & $0,848^{* *}$ & $2,256^{* *}$ \\
Interação & 20 & $0,328^{* *}$ & $277,0^{\text {ns }}$ & $1,118^{\text {ns }}$ & $0,003^{\text {ns }}$ & $0,008^{\text {ns }}$ & $0,174^{* *}$ & $0,573^{* *}$ \\
Resíduo & 30 & 0,088 & 6661,2 & 1,332 & 0,004 & 0,004 & 0,06 & 0,183 \\
\hline Média Geral & - & 1,39 & 85,81 & 13,48 & 0,698 & 3,67 & 2,65 & 4,48 \\
\hline C.V. $(\%)$ & - & 21,3 & 17,3 & 8,5 & 10,5 & 1,8 & 9,3 & 9,5 \\
\hline
\end{tabular}

${ }^{* \star}(\mathrm{p}<0,01) ;{ }^{*}(\mathrm{p}<0,05) ; \mathrm{ns}$ (não significativo). C.V.: coeficiente de variação. PM: perda de massa (\%), AA: ácido ascórbico (mg de ácido ascórbico $100 \mathrm{~g}^{-1}$ de polpa); SS: sólidos solúveis (ํBrix); AT: acidez titulável (g de ácido cítrico $100 \mathrm{~g}^{-1}$ de polpa); AR: açúcar redutor (\%); AV: aparência visual (notas).

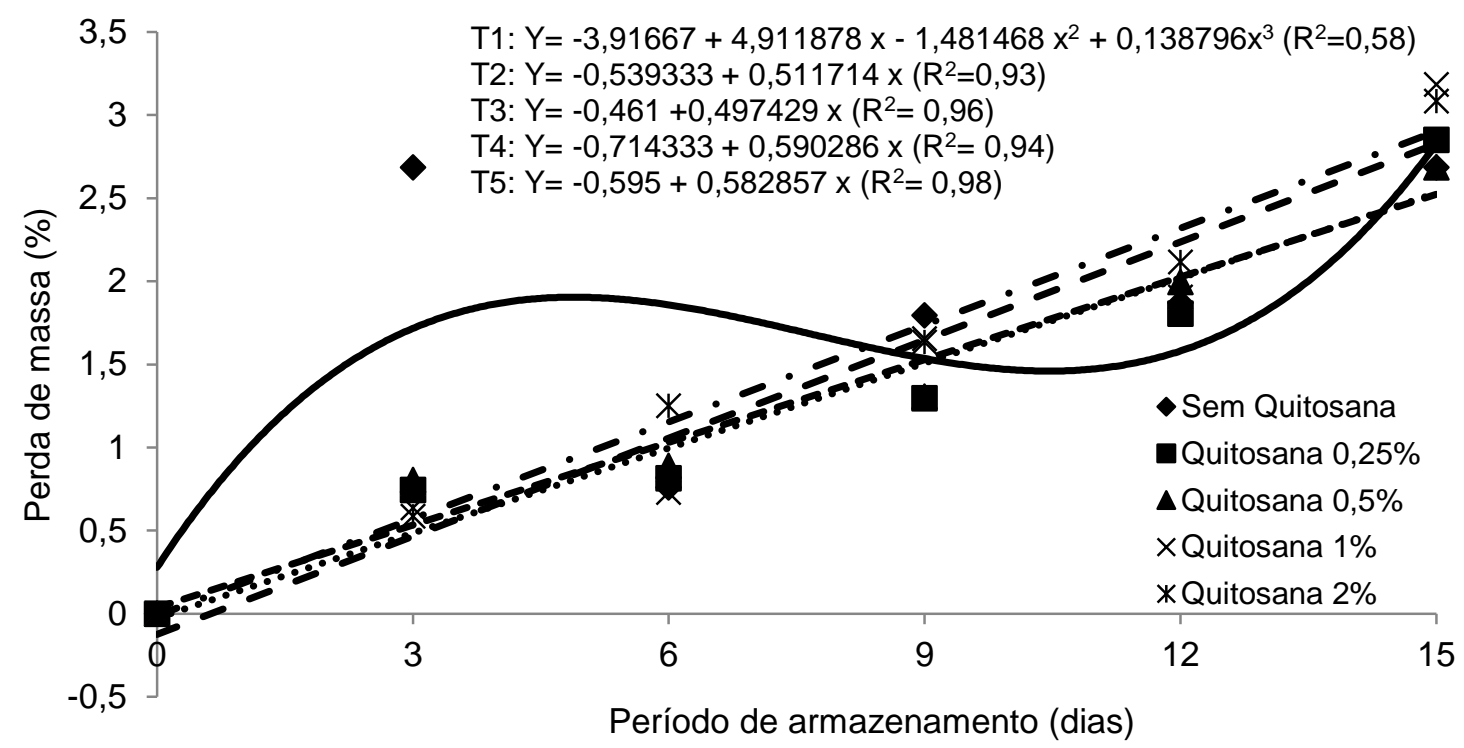

Figura 1 - Perda de massa (\%) dos frutos de mangabeira sob ação de concentrações de filmes de quitosana $(0,25 \% ; 0,5 \%$; $1 \%$ e $2 \%)$, ao longo de 15 dias de armazenamento a $3 \pm 1{ }^{\circ} \mathrm{C}$ e $80 \pm 1 \%$ de UR. Illha Solteira, 2013. Loss of mass (\%) of mangaba fruit in chitosan film concentration action $(0.25 \%, 0.5 \%, 1 \%$ and $2 \%$ ) and control, for 15 days of storage at $3 \pm 1{ }^{\circ} \mathrm{C}$ and $80 \pm 1 \% \mathrm{RH}$. Illha Solteira, 2013.

Para o teor de ácido ascórbico (mg de ácido ascórbico $100 \mathrm{gg}^{-1}$ de polpa) (Figura 2), houve decréscimo ao longo do período de armazenamento (15 dias), chegando ao final com teor de $74,7 \mathrm{mg}$ de ácido ascórbico $100 \mathrm{~g}^{-1}$ de polpa. É sabido que ocorre diminuição dos teores de ácido ascórbico em razão do amadurecimento dos frutos, devido à ação da enzima ácido ascórbico oxidase e enzimas oxidativas, como a peroxidase. Esses teores podem ser oxidados em ácido deidroascórbico, ainda com 
atividade vitamínica ou degradado para ácido 2,3-dicetogulônico, perdendo sua atividade biológica (Chitarra \& Chitarra, 2005; Souza et al., 2011). Concorda-se com Hojo et al. (2011), que, em pesquisa com lichias mantidas em embalagens plásticas e submetidas a imersão de quitosana a 0,5\%, observaram redução dos teores de ácido ascórbico durante 24 dias de armazenamento a $5^{\circ} \mathrm{C}$. Os autores associam essa redução do ácido ascórbico à senescência dos frutos.

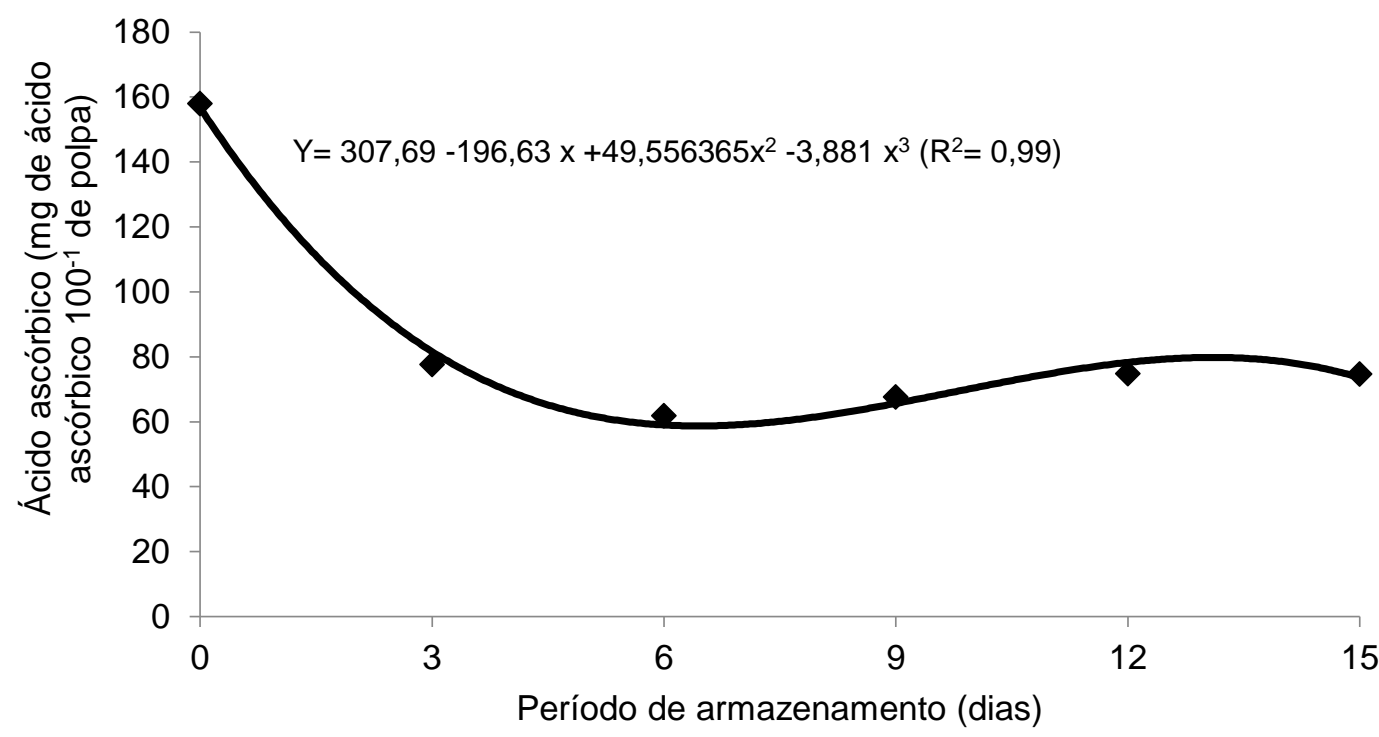

Figura 2 - Teores de ácido ascórbico (mg de ácido ascórbico $100 \mathrm{~g}^{-1}$ de polpa) em frutos de mangabeira ao longo de 15 dias de armazenamento a $3 \pm 1{ }^{\circ} \mathrm{C}$ e $80 \pm 1 \%$ de UR. Ilha Solteira, 2013. Ascorbic acid content ( $\mathrm{mg}$ of ascorbic acid $100 \mathrm{~g}^{-1}$ of pulp) of mangaba fruit for 15 days of storage at $3 \pm 1{ }^{\circ} \mathrm{C}$ and $80 \pm 1 \% \mathrm{RH}$. Ilha Solteira, 2013.

Para acidez titulável (Figura 3), observou-se diminuição dos teores durante o período de armazenamento, chegando aos 15 dias com 0,689 $\mathrm{g}$ de ácido cítrico $100 \mathrm{~g}^{-1}$ de polpa. Esse comportamento, provavelmente, é decorrente do amadurecimento dos frutos. Chitarra \& Chitarra (2005) citam que o teor de ácidos em vegetais diminui com o amadurecimento, pois estes são utilizados como substrato na respiração ou transformados em açúcares. E ainda apresenta importante papel no sabor e no aroma dos frutos. O mesmo ocorreu com Tezotto-Uliana et al. (2014) em framboesas e com Souza et al. (2011) em mangas cv. Tommy Atkins e aplicação de quitosana. Nesses trabalhos os autores observaram a diminuição da acidez titulável ao longo do armazenamento.

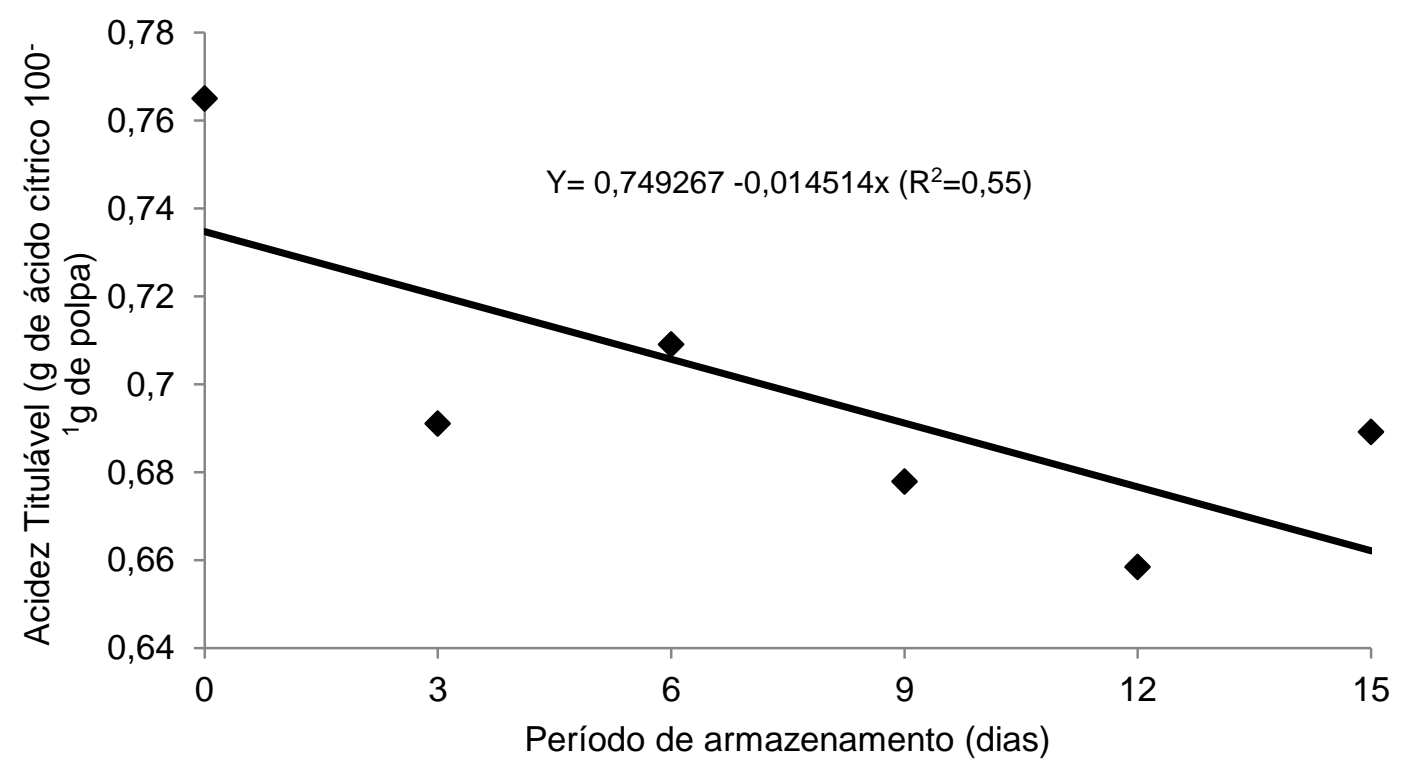

Figura 3 - Teores de acidez titulável (g de ácido cítrico $100 \mathrm{~g}^{-1}$ de polpa) em frutos de mangabeira ao longo de 15 dias de armazenamento a $3 \pm 1{ }^{\circ} \mathrm{C}$ e $80 \pm 1 \%$ de UR. Ilha Solteira, 2013. Titratable acidity content ( $g$ of citric acid $100 \mathrm{~g}^{-1}$ of pulp) of mangaba fruit for 15 days of storage at $3 \pm 1{ }^{\circ} \mathrm{C}$ and $80 \pm 1 \% R H$. Ilha Solteira, 2013. 
Nos valores de $\mathrm{pH}$ (Figura 4), houve pequeno incremento ao final do período de armazenamento $(3,75)$. Com a diminuição dos teores de acidez titulável, é esperado que os valores de $\mathrm{pH}$ aumentem nos frutos, como ocorreu na pesquisa. Chitarra \& Chitarra (2005) apontam que, dentro da faixa de concentração de 2,5 a 0,5\%, o pH aumenta com a diminuição da acidez titulável. Discordando da pesquisa, Hernández-Muñoz et al. (2008) citaram aumento no valor do $\mathrm{pH}$ somente nos frutos não tratados com quitosana.

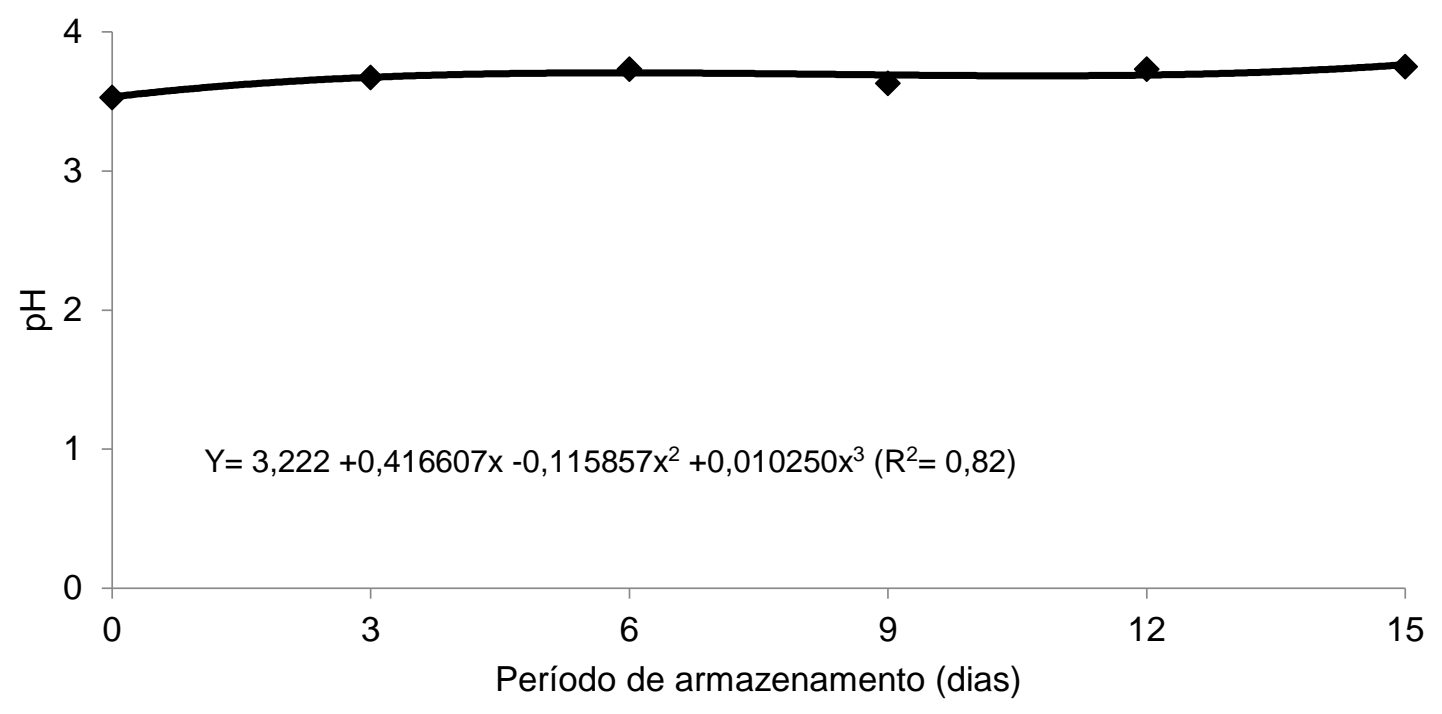

Figura 4 - Valores de $\mathrm{pH}$ em frutos de mangabeira ao longo de 15 dias de armazenamento a $3 \pm 1{ }^{\circ} \mathrm{C}$ e $80 \pm 1 \%$ de UR. Ilha Solteira, 2013. Mangaba fruit $\mathrm{pH}$ values for 15 days of storage at $3 \pm 1{ }^{\circ} \mathrm{C}$ and $80 \pm 1 \% R H$. Ilha Solteira, 2013 .

Entre os tratamentos e o período de armazenamento (Figura 5), nota-se em todos os tratamentos incremento nos teores de açúcar redutor ao final do armazenamento, chegando aos 15 dias com $2,4 \%, 2,5 \%, 2,7 \%, 2,5 \%$ e $2,8 \%$ de glicose (testemunha, $0,25 \% ; 0,5 \% ; 1 \%$ e $2 \%$, respectivamente). Contudo, é possível observar que, no tratamento com aplicação de $2 \%$ de quitosana, o aumento do açúcar foi efetivamente menor até o nono dia; provavelmente, esse tratamento fez com que diminuísse a respiração do fruto e, com isso, a degradação dos carboidratos via glicólise. $\mathrm{O}$ emprego de revestimentos modifica a atmosfera ao redor dos frutos, diminuindo a atividade respiratória, mantendo a qualidade e estendendo o armazenamento (Chitarra \& Chitarra, 2005).

Estão estes resultados de acordo com Soares et al. (2011), que, em pesquisa com goiaba cultivar Pedro Sato e coberturas comestíveis de quitosana a $1,5 \%$ e fécula de mandioca a $1,0 \%$, citaram elevação nos valores de açúcar redutor. Oshiro et al. (2012), em trabalho com goiabas Pedro Sato, buscando determinar os efeitos de revestimentos (quitosana e gelatina) e da refrigeração (5 ${ }^{\circ} \mathrm{C}$ e $10^{\circ} \mathrm{C}$ ), observaram aumento nos teores de açúcar redutor em todos os tratamentos, até os 21 dias, concluindo que as películas não foram efetivas no controle do amadurecimento.

$\mathrm{Na}$ interação dos tratamentos com o tempo de armazenamento (Figura 6), observam-se decrés- cimos nas notas dos tratamentos-controle, $0,25 \%$, $0,5 \%$ e $1 \%$ de quitosana, partindo da nota 5 (ótimo), chegando ao final com nota 3 (regular), 4 (bom), 3 (regular) e 4 (bom), respectivamente. Entretanto, o tratamento com $2 \%$ de quitosana recebeu notas máximas em todos os períodos de avaliação ( $5=$ ótimo). Conforme Chitarra \& Chitarra (2005), a respiração e a produção de etileno pelos tecidos ocorrem imediatamente após a colheita, promovendo reações químicas e bioquímicas responsáveis pelas modificações da qualidade sensorial (cor, sabor, aroma e textura).

Resultados semelhantes foram citados por Hojo et al. (2011), que, estudando lichias em embalagens plásticas e imersão em quitosana $0,5 \%$, notaram que os frutos tratados com quitosana obtiveram nota máxima ao longo do período de armazenamento. Cerqueira et al. (2011), em trabalho com goiaba Kumagai e recobrimentos proteicos e quitosana, observaram a presença de brilho em todos os frutos tratados, sendo mais intenso nas coberturas com maiores concentrações de solutos.

E ainda Benhabiles et al. (2013), utilizando quitosana na pós-colheita de morangos armazenados em temperatura ambiente, citaram que os frutos tratados apresentaram menores perdas de massa e retenção do brilho. Os frutos tratados com $1 \%$ de quitosana tiveram melhor aceitação pelos avaliadores, quando comparados ao controle. 


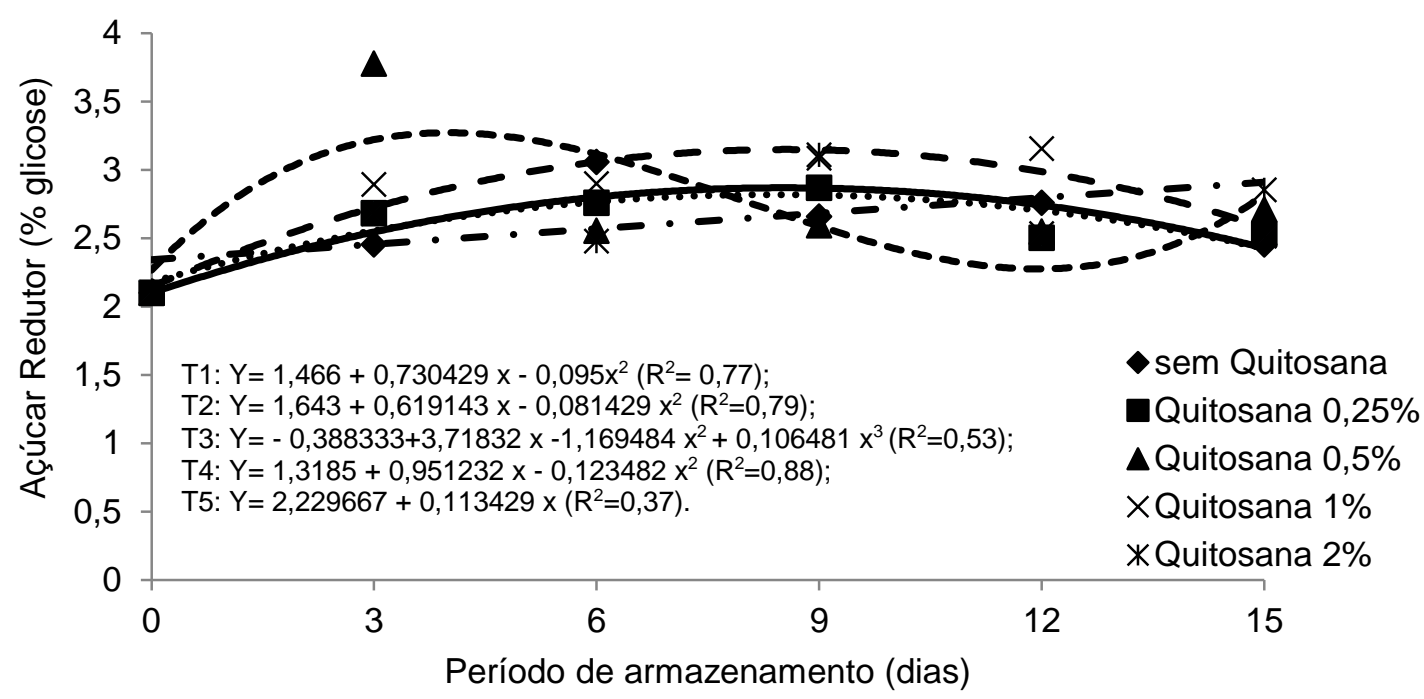

Figura 5 - Teor de açúcar redutor (\%glicose) dos frutos de mangabeira sob ação de concentrações de filmes de quitosana $(0,25 \% ; 0,5 \% ; 1 \%$ e $2 \%)$, ao longo de 15 dias de armazenamento a $3 \pm 1{ }^{\circ} \mathrm{C}$ e $80 \pm 1 \%$ de UR. Ilha Solteira, 2013. Reducing sugar (\% of glucose) of mangaba fruit in chitosan film concentration action $(0.25 \%, 0.5 \%, 1 \%$ and $2 \%)$ and control, for 15 days of storage at $3 \pm 1{ }^{\circ} \mathrm{C}$ and $80 \pm 1 \% R H$. Ilha Solteira, 2013.

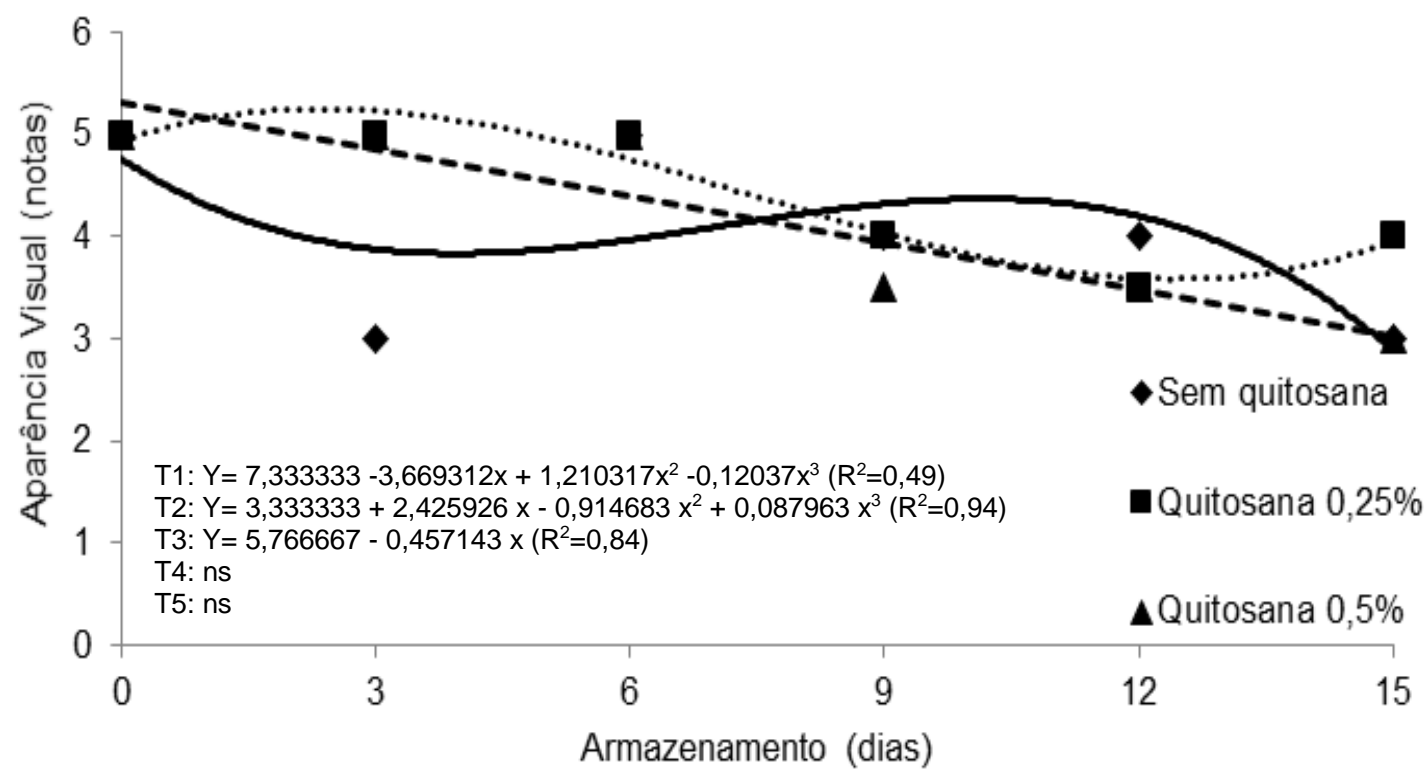

Figura 6 - Aparência visual (notas) dos frutos de mangabeira sob ação de concentrações de filmes de quitosana $(0,25 ; 0,5 ; 1$ e $2 \%)$, ao longo de 15 dias de armazenamento a $3 \pm 1{ }^{\circ} \mathrm{C}$ e $80 \pm 1 \%$ de UR. Ilha Solteira, 2013. Visual appearance (score) of mangaba fruit in chitosan film concentration action $10.25 \%$, $0.5 \%, 1 \%$ and $2 \%$ ) and control, for 15 days of storage at $3 \pm 1{ }^{\circ} \mathrm{C}$ and $80 \pm 1 \% R H$. Ilha Solteira, 2013.

\section{Conclusões}

Aplicação de quitosana nas concentrações de $1 \%$ e $2 \%$ mostra-se efetiva na aparência visual de frutos de mangaba, no estádio de vez e acondicionados em bandeja de poliestireno expandido, recobertas com filme PVC, armazenadas a $3 \pm 1{ }^{\circ} \mathrm{C}$ e $80 \pm 1 \%$ de umidade em BOD, permitindo armazená-las por 15 dias.

O uso da quitosana na pós-colheita das mangabas no estádio de vez proporcionou menor perda de massa até o sexto dia de armazenamento. E o aumento do teor de açúcar redutor foi efetivamente menor até o nono dia de armazenamento em frutos que receberam aplicação de $2 \%$ de quitosana, evidenciando menor velocidade de amadurecimento.

\section{Agradecimentos}

À Fundação de Amparo à Pesquisa do Estado de São Paulo (FAPESP), pelo apoio concedido para a realização do trabalho. 


\section{Referências}

Bautista-Baños S, Hernández-Lauzardo AN, Velázquez-Del Valle MG, Hernández-López $M$, Barka, EA, Bosquez-Molina E, Wilson CL (2006) Chitosan as a potential natural compound to control pre and postharvest diseases of horticultural commodities. Crop Protection 25: 108-118.

Benhabiles MS, Drouiche N, Lounici H, Pauss A, Mameri N (2013) Effect of shrimp chitosan coatings as affected by chitosan extraction processes on postharvest quality of strawberry. Journal of Food Measurement and Characterization 7(4): 215-221.

Carnelossi MAG, Sena HC, Narain N, Yaguiu P, Silva GF (2009) Physico-Chemical Quality Changes in Mangaba (Hancornia speciosa Gomes) Fruit Stored at Different Temperatures. Brazilian Archives of Biology and. Technology. 52(4): 985-990.

Cerqueira TS, Jacomino AP, Sasaki FF (2011) Recobrimento de goiabas com filmes proteicos e de quitosana. Bragantia 70(1): 216-221.

Cardoso LM, Reis BL, Oliveira DS, Pinheiro-Sant'ana HM (2014) Mangaba (Hancornia speciosa Gomes) from the Brazilian Cerrado: nutritional value, carotenoids and antioxidant vitamins. Fruits 69: 89-99.

Chitarra, MIF, Chitarra, AB (2005) Pós-colheita de frutas e hortaliças: fisiologia e manuseio. UFLA. 783p.

Durigan JF (2013) Pós-colheita de frutas. Revista Brasileira de Fruticultura 35(2): p.i.

Embrapa - Empresa Brasileira de Pesquisa Agropecuária (2010) Frutas nativas da região Centro-oeste do Brasil. Embrapa Informação Tecnológica. Brasília. 322 p.

Ferreira DF (2010) SISVAR - Sistema de Análise de Variância. Versão 5. 3. UFLA.

Ferreira APS, Isepon JS, Moreira ER, Atílio LB, Boliani AC (2010) Qualidade pós-colheita do pseudofruto do cajueiro sob ação de quitosana e refrigeração. Cultura Agronômica 19(1): 64-70.

Hernández- Muñoz P, Almenar E, Del Valle V, Velez D, Gavara, R (2008) Effect of chitosan coating combined with postharvest calcium treatment on strawberry (Fragaria ananassa) quality during refrigerated storage. Food Chemistry 110(1): 428-435.
Hojo ETD, Durigan JF, Hojo RH (2011) Uso de embalagens plásticas e cobertura de quitosana na conservação pós-colheita de lichias. Revista Brasileira Fruticultura 33(n.spe 1): 377-383.

Hong K, Xie J, Zhang L, Sun D, Gong D (2012) Effects of chitosan coating on postharvest life and quality of guava (Psidium guajava L.) fruit during cold storage. Scientia Horticulturae 144: 172-178.

Instituto Adolfo Lutz (1985) Normas analíticas do Instituto Adolfo Lutz. I - Métodos químicos e físicos para análise de alimentos. São Paulo. 533p.

Narain, N.; Ferreira, D. (2003) Tecnologia de alimentos aplicada à mangaba. In: Simpósio brasileiro sobre a cultura da mangaba, 1., 2003, Aracajú. Anais... Aracajú: Embrapa Tabuleiros Costeiros, 1CD-ROM.

Oshiro AM, Dresch DM, Scalon SPQ (2012) Preservação de goiabas 'Pedro Sato' armazenadas sob atmosfera modificada em refrigeração. Revista de Ciências Agrárias 35(1): 213-221.

Pereira, A. V.; Pereira, E. B. C.; Silva Júnior, J. F.; Silva, D. B. (2010) Mangaba. In: Frutas nativas da região Centro-Oeste do Brasil. Brasília: Embrapa Informação Tecnológica, p. 242.

Silva Junior JF (2004) A cultura da mangaba. Revista Brasileira Fruticultura 26(1): p. i.

Soares NFF, Silva DFP, Camilloto GP, Oliveira CP, Pinheiro NM, Medeiros EAA (2011) Uso de revestimento comestível e conservação pós-colheita de goiaba. Revista Brasileira de Fruticultura 33 (n. spe 1): 281-289.

Souza ML, Morgado CMA, Marques KM, Mattiuz CFM, Mattiuz BH (2011) Pós-colheita de mangas 'Tommy Atkins' recobertas com quitosana. Revista Brasileira de Fruticultura 33(n. spe 1): 337-343.

Tezotto-Uliana JV, Fargoni GP, Geerdink GM, Kluge RA (2014) Chitosan applications pre-or postharvest prolong raspberry shelf-life quality. Postharvest Biology and Technology 91(1): 72-77.

Vieira RF, Agostini-Costa TS, Silva DB, Sano SM, Ferreira, FR (2010) Frutas nativas da região Centrooeste do Brasil. Embrapa Informação Tecnológica. 322p. 